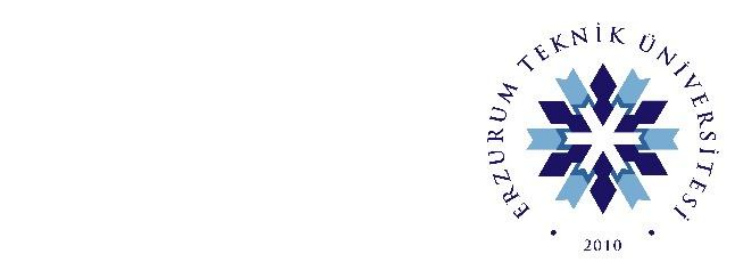

\title{
OSMANLI KARA ORDUSUNDA KİRPAS KULLANIMINA GENEL BİR BAKIŞ (1752-1836)
}

\section{OVERVIEW USE OF KIRPAS IN THE ARMY OF OTTOMAN LAND}

(1752-1836)

\section{BURAK KOCAOĞLU}

Dr. Öğr. Üyesi, Osmaniye Korkut Ata Üniversitesi, Kadirli Sosyal ve Beşeri Bilimler Fakültesi Bilgi ve Belge Yönetimi Bölümü burakkocaoglu06@gmail.com

(iD) https://orcid.org/0000-0002-0595-7229

\author{
ETÜ Sosyal Bilimler Enstitüsü Dergisi | ETU Journal of Social Sciences Institute \\ S.8, Nisan | April 2019, Erzurum \\ ISSN: 2149-939X

$\begin{array}{ll}\text { Makale Türü } \mid \text { Article Types } & : \text { Araştırma Makalesi |Research Article } \\ \text { Geliş Tarihi } \mid \text { Received Date } & : 03.11 .2018 \\ \text { Kabul Tarihi | Accepted Date } & : \text { 27.03.2019 } \\ \text { Sayfa |Pages } & : \text { 33-44 } \\ \text { DOI- } & : \text { http://dx.doi.org/10.29157/etusbe.76 }\end{array}$

This article was checked by 



\title{
OSMANLI KARA ORDUSUNDA KİRPAS KULLANIMINA GENEL BİR BAKIŞ (1752-1836)
}

\author{
Burak KOCAOĞLU
}

ETÜSosyal Bilimler Enstitüsü Dergisi (ETÜSBED), S.8, Nisan 2019, Sayfa:3344

\section{ÖZET}

Osmanlı Devleti'nin döneminin güçlü ve kalabalık ordularından birine sahip olduğuna dair bilgiler birçok kaynakta geçmektedir. Kaynaklar genellikle bunu ordunun insan kaynağının çokluğuna ve iaşe ve ikmal konusunda sıkıntı yaşamamasına bağlamıştır. Ancak iaşe ve ikmal kısmının içeriği tam anlamıla doldurulamamıştır. Özellikle hangi iaşe ve ikmal malzemesinin nasıl ve hangi yollarla temin edildiği, temin edilen malzemenin ordunun hangi alanında ne türde kullanıldığı sıklıkla göz ardı edilmiştir. İşte göz ardı edilen ikmal malzemelerinden biri de pamuk ipliğinden dokunan kirpas adı verilen kumaş türüdür. Genel olarak donanmada gemilerin yelkenleri için kullanılan kirpas, Osmanlı kara ordusunda da kullanılmıştır. Bu kumaş türü Anadolu'nun çeşitli bölgelerinde üretilmiş olup, kara ordusunun çeşitli kısımlarına gönderilmiştir. Biz bu çalışmamızda kirpas adı verilen kumaş türünün Osmanlı kara ordusunda ne şekilde kullanıldığını ve nasıl temin edildiğini arşiv kaynaklarına dayanaraktan genel bir çerçeve içerisinde göstermeye çalışacă̆ız.

Anahtar Kelimeler: Kirpas, Mübayaa, Çadır, Ordu, Top.

\section{OVERVIEW USE OF KIRPAS IN THE ARMY OF OTTOMAN LAND}

\section{(1752-1836)}

\begin{abstract}
The fact that the Ottoman Empire had one of its powerful and crowded armies is well known in many sources. Sources usually link this to the abundance of human resources and the difficulty of subsistence and supply. However, the contents of the subsistence and supply part can not be fully filled. In particular, it has often been overlooked how and in which way the supply of supplies and supplies is provided, and in what area the supplied material is used in the area of the army. One of the supply materials that are ignored is the type of fabric called kirpas, which is woven from cotton yarn. The kirpas, which are generally used for sailing vessels in the navy, have also been used in the Ottoman land army. This fabric was produced in various regions of Anatolia and sent to various parts of the land army. In this work, we will try to show in a general framework based on archive resources how and how the fabric type called kirpas is used in the Ottoman land army.
\end{abstract}

Keywords: Kirpas, Purchase, Tent, Army, Cannon. 


\section{Giriş}

Askeri operasyonların başarıya ulaşmasında ve ülkenin korunmasında, muharip güçlerin teknik donanımı, talim ve disiplinlerinin yanı sıra, sefer öncesi ve sonrası yapılan hazırlıkların da tesiri vardır. Günümüze kıyasla nakil ve haberleşme vasıtalarının son derece ilkel ve tamamen insan ve hayvan gücüne dayalı yürütüldüğü devirlerde bu tür hazırlıklar daha da ehemmiyet kazanmıştır. Günümüzde lojistik olarak adlandırılan, sefer öncesi ve sefer sırasında yürütülen bu faaliyetler Osmanlı askeri tarihi literatüründe iaşe ve ikmal olarak geçmektedir. ${ }^{1}$ İaşe ve ikmal meselesi savaşın sonucunu doğrudan etkileyen konulardır. Bu nedenle yaşadığı dönemin kalabalık ordularından birine sahip olan Osmanlı Devleti2 iaşe ve ikmal konusu üzerinde ehemmiyetle durmuştur. ${ }^{3}$ Batılı kaynaklarda da belirtildiği üzere Osmanlı askerleri, yükselme döneminde herhangi bir başka Avrupa Devletinin ordusundan daha iyi ikmal koşullarına sahip ${ }^{4}$ olmasına karşın duraklama ve çöküş dönemlerinde ${ }^{5}$ bu iyi durumdan söz etmemiz pek mümkün değildir. ${ }^{6}$

Ordunun iaşe ve ikmal malzemeleri çok geniş kapsamlı olup çeşitli kaynaklardan temin edilen malzemeleri alt alta sıralamaya kalktığımızda malzemelerin listesi yüzlerce madde olarak karşımıza çıkabilir. Bu malzemelerden biri olan kirpas denen kumaş türü göreceli olarak çoğu ikmal malzemesine göre önemsiz olarak görünse bile, bu malzeme gerek donanmada ${ }^{7}$ gerekse kara ordusunda yoğun bir şekilde kullanılmıştır.

\footnotetext{
1 Ömer İşbilir, "Osmanlı Ordularının İaşe ve İkmali: I. Ahmed Devri İran Seferleri Örneği", Türkler, C.10, (Edt. Hasan Celal Güzel) Yeni Türkiye Yayınları, Ankara 2002, s.278.

2 Gabor Agoston, Osmanlı' da Strateji ve Askerî Güç, (Çev. M. Fatih Çalışır) Timaş Yayınları, İstanbul, 2015, s. 246-247.

${ }^{3}$ Gültekin Yıldız, "Kara Kuvvetleri", Osmanlı Askeri Tarihi Kara, Deniz ve Hava Kuvvetleri 1792-1918, (Edt. Gültekin Yıldız), Timaş Yayınları, İstanbul, 2017, s. 65.

${ }^{4}$ Kenneth Chase, Ateşli Silahlar Tarihi, (Çev. Füsun Tayanç), Türkiye İş Bankası Kültür Yayınları, İstanbul, 2008, s.111.

5 Vırgını. H.Aksan, Kuşatılmış Bir İmparatorluk Osmanlı Harpleri 1700-1870, (Çev. Gül Çağalı Güven), Türkiye İş Bankası Kültür Yayınları, İstanbul, 2011, s.156-157.

${ }_{6}$ Osmanlı Devleti'nde askeri harcamaların ve sefer hazırlıklarının bütçeye etkisini görmek için bknz. Ahmet Tabakoğlu, Osmanlı Mali Tarihi, Dergah Yayınları, İstanbul, 2016.

7 Yusuf Alperen Aydın, "XVII. Yüzyıl Başlarında Osmanlı Donanması ve Tersâne-i Âmire'de Lenger ve Yelken Bezi Üretimine Başlanması" Tarih Dergisi, S.49, İstanbul, 2010, s. 54.
} 


\section{I- Osmanlı Kara Ordusunda Kirpas Kullanımı}

Pamuk ipliğinden dokunan ve ham bez anlamına gelen kirpas ${ }^{8}$ çoğunlukla donanmada gemilerin ${ }^{9}$ yelkenleri ${ }^{10}$ için belirli standartlar baz alınarak üretilmiştir. ${ }^{11}$ Ancak, kirpasın Osmanlı ordusunda tek kullanım alanı donanma olmamış, kara ordusunda da yoğun bir şekilde kirpas kullanılmıştır. Kara ordusunda kirpasın en çok kullanıldığı alan sefer zamanında askerlerin çadırlarının kurulması sırasında olmuştur. Sefer zamanında askerlerin çadırlarının kurulması ve eskiyen çadırların tamir işi Mehterhâne-i Âmire' nin ${ }^{12}$ üzerinde olup, bu meşakkatli iş mehterbaşı tarafından organize edilmiştir. ${ }^{13}$

Temin edilecek olan kirpas, görevlendirilmiş olan mübaşirler tarafından ${ }^{14}$, devlet tarafından piyasa fiyatının altında ${ }^{15}$ belirlenen birim fiyat üzerinden mübayaa edilip16, İstanbul'a teslim edilmiştir. ${ }^{17}$ Kirpasların bedelleri tek bir kaynaktan karşılanmamış olup, çeşitli bölgelere ait mukataa ${ }^{18}$ ve cizye $^{19}$ gibi gelirlerden ya da doğrudan hazine tarafından karşılanmıştır.

Mehterhane için gerekli olan on binlerce top kirpasın temininde İstanbul ${ }^{20}$ ve İstanbul'a kısmen uzak sayılabilecek üretim yerlerinden faydalanılmıştır. Bu yerlerin başında gelen Diyarbakır'dan temin edilecek kirpasların İstanbul'a

8 İdris Bostan, Osmanlı Bahriye Teşkilâtı:XVII. Yüzyılda Tersâne-i Amire, T.T.K., Ankara, 2003, s. 154.

9 Osmanlı donanmasının XVIII. yüzyıldan itibaren kadırgadan kalyona geçişi, yelken bezi ihtiyacını oldukça arttırmıştır. Daniel Panzac, Osmanlı Donanması (1572-1923), (Çev. Ahmet Maden-Sertaç Canpolat), İş Kültür Yayınları, İstanbul, 2018, s.241.

10 BOA., C.BH., 87-4192. / BOA. C.BH., 259-11997.

11 BOA., C.BH.,104-5034., 1 top kirpasin 15 zira (75 - $90 \mathrm{~cm}$ arası) ve 1020 dirhem $(1$ dirhem = 3,2 gr) olması istenmiştir.

12 Bu konu hakkında ayrıntılı bilgi için bknz. Ahmet Yaramış, "Mehterhâne-i Âmire Ocă̆ı'nın Islahı(1826)", Afyon Kocatepe Üniversitesi SBD., C.15-S.1, 2013.

13 BOA., C.İKTS. 11-539.

14 BOA., C.AS., 385-15916., H.1223 senesinde çadırlık 2000 top kırmızı kirpas, tüccarlardan topu 150 paradan toplamda 7500 kuruşa (300.000 para / 1 Kuruş : 40 Para) alınmıştır.

15 Mehmet Genç, Osmanlı İmparatorluğunda Devlet ve Ekonomi, Ötüken, İstanbul, 2014, s. 246.

16 BOA., C.AS. 170-7454., H.1215 senesinde Mehterhaneye verilecek olan kirpasların topu 2 kuruş üzerinden Soma'dan mübayaa edilmiştir.

17 BOA., İE.SM. 24-2502.

18 BOA., AE.SAMD.III. 218-21030.

19 BOA., AE.SAMD.III. 147-14414.

${ }^{20}$ BOA. C.AS. 588-24760., Hz. Halid (Eyüp Sultan) civarında kurulmuş olan rişte (tel) hanede yeni icat kirpas üretiminde yer alacak olan işçilerin ve çeşitli görevlilerin maaşları ve çeşitli harcamalar için H. 1251 yılının Rabiulevvel ayı için Tersâne-i Âmire hazinesinden 2142,5 kuruş 9 para ödeme yapılmıştır. / BOA., C.AS. 104-4714., Yine Hz. Halid (Eyüp Sultan) civarında kurulmuş olan rişte (tel) hanede yeni icat kirpas üretiminde yer alacak olan işçilerin ve çeşitli görevlilerin maaşları ve çeşitli harcamalar için H. 1251 yılının Şevval ayı için Tersâne-i Âmire hazinesinden 1781 kuruş ödeme yapılmıştır. 
gönderilmesi sırasında işlerin sorunsuz bir şekilde hallolması için bölge valisine, kadısına ve mübayaa işinden sorumlu olan mübaşirlere hükümler gönderilmiştir. ${ }^{21}$ Ayrıca Diyarbakır dışında Soma ve çevresi de devletin önemli kirpas temin merkezleri arasında yer almıştır. ${ }^{22}$

Ağırlığı tonları bulan on binlerce top kirpasın imal edildiği yerden İstanbul'a nakledilmesi önemli konuların başında gelmiştir. Nakliye sırasında üretim merkezinin (Gelibolu ve Soma) denize kıyısı varsa ya da kıyıya yakın bir yerdeyse kirpasın İstanbul'a nakliyesi deniz yoluyla yapılmıştır. Kirpasların gemilere yüklenmesinde ve yükün İstanbul'da boşaltılıp Mehterhaneye teslimi sırasında arka hamalları kethüdasına emir gönderilmiş ve nakliye sırasında gerekli olacak olan, sayıları bini aşan arka hamalın ${ }^{23}$ temini sağlanmıştır. ${ }^{24} \mathrm{Kimi}$ zaman istenilen on binlerce top kirpasın tek seferde temin edilip İstanbul'a gönderilmesi mümkün olmamış, istenilen kirpasın birkaç seneye yayılarak parça parça İstanbul'a gönderildiği durumlar da olmuştur. ${ }^{25} \mathrm{Bu}$ şekilde çeşitli bölgelerden parça parça getirilen kirpasların naklinde bazı zamanlar sıkıntılar da yaşanmıştır. Yaşanan sıkıntıların başında parça parça deniz yolu ile İstanbul'a gönderilen kirpasların İstanbul'a istenen miktardan az gönderilmesi veya yolda kirpasın zayi olması gelmiştir. Böyle bir durumda eksik gönderilen kirpasın miktarı belirlenip, bedeli, miri mübayaa fiyatı üzerinden tespit edilerek, mübayaa işinden sorumlu olan görevliden zararın tahsili yoluna gidilmiştir. ${ }^{26}$ Bu şekilde sert sayılabilecek bir yaptırımla, daha sonra yapılacak olan alımlarda yaşanabilecek olumsuzlukların önüne geçilmeye çalışılmıştır.

Sefere katılan askerlerin konaklamaları için hazırlanan çadırların dışında padişahın bizzat sefere katıldığı zaman padişah için hazırlanan Otağ-1 Hümayun adı verilen çadırın hazırlanması içinde yüklü miktar da kirpas

21 BOA., AE. SMHD.II. 111-9532., H.1215 senesinde Soma ve havalisinden topu 2 kuruş üzerinden 20.000 top kirpasın mübayaa edilmesi emredilmiştir.

22 BOA., C.AS. 170-7454

23 Yükü sırtında semerle taşıyan hamallar.

24 BOA., C.AS. 561-23568., H.1244 ve 1245 tarihlerinde arka hamalları kethüdası vasıtasıyla 1036 hamal 6 akçe yevmiyeyle görevlendirilmiştir.

25 BOA., C. İKTS. 17-808.

26 BOA., C.ML. 4-146., Mahterhane için H.1225 ve 1227 senelerinde Soma ve havalisinden 80.000 top kirpasın mübayaa edilmesi emredilmiştir. Mübayaa işiyle görevlendirilmiş olan Bekir adında mübaşir H.1225 yılında 40.000 top kirpası parça parça İstanbul'a göndermeye çalışmıştır. Ancak 581 top kirpas zayi olup yapılan inceleme soncunda tenzilata gidilip zayi olan kirpasın bedeli görevlilerden talep edilmiştir. 
gerekmiştir. ${ }^{27}$ Şayet sultan sefere katılmışsa yeniçeriler çadırlarını Otağ-1 Hümayunun iki tarafına kurmuşlardır. ${ }^{28}$

III. Selim Döneminde, Nizâm-1 Cedîd adıyla kurulan ve Levend Çiftliğinde eğitim gören askerlere yapılacak çadırlar için ${ }^{29}$ de uzunluğu yüzlerce zirayı ${ }^{30}$ bulan kirpas yoğun bir şekilde talep edilmiştir. ${ }^{31}$ Talep edilen miktarda kirpas mehterhane mevcudundan sağliklı bir şekilde temin edilmiştir. ${ }^{32}$

Çadırların hazırlanması dışında, sefer sırasında orduya gönderilecek olan zahirelerin doldurulacağı çuvalların hazırlanmasında da çeşitli türden kirpas kullanılmıştır. Çuvalların hazırlanması için yapılmış olan kirpas alımlarında kaç adet çuvalın hangi birim fiyat üzerinden alındığı belirtilmiştir. ${ }^{33}$

Kirpas adı verilen kumaşın kara ordusunda bir diğer kullanım alanı ise çeşitli türden patlayıcıların hazırlanması sırasında olmuştur. Özellikle çeşitli türden barutların perdaht (cila) edilmesinde ${ }^{34}$ ve topların atılması için tek atımlık olarak hazırlanmış olan hartuç keselerinin ${ }^{35}$ yapımında kirpas yoğun bir şekilde talep edilip kullanılmıştır. ${ }^{36}$

Kirpas sadece sefer sırasında ya da eğitim sırasında kullanılmamış olup, ayrıca Serasker takımı ve Liva-ı Şerif takımı ${ }^{37}$ adı verilen, sefer sırasında Hz.

27 BOA., İE.DH 16-1450.

28 İsmail Hakkı Uzunçarşılı, Osmanlı Devleti Teşkilâtından Kapukulu Ocakları, C.I, T.T.K., Ankara, 1988, s. 364.

29 BOA., C.AS.974-42449., H.1216 senesinde Levend Çiftliğine ihtiyaten Mehterhaneden gönderilecek olan İngilizkavi kirpaslarının 5 zira uzunluğunda olması istenmiştir. Bu kirpaslardan 45 kıta çadır yapılmıştır. Bu işlerin yapılması için toplam 121.200 akçe (1010 kuruş 1 kuruş : 120 akçe) harcama yapılmıştır

30 Osmanlı döneminde kullanılan ölçü birimlerini görmek için bknz. Halil İnalcık, Osmanlı İmparatorluğu'nun Ekonomik ve Sosyal Tarihi, C.1, Eren Yayınları, İstanbul, 2009.

31 BOA., C.AS. 1114-49355., H.1207 senesinde, Levend Çiftliğinde bulunan Bostancılar için her biri 260 ziradan 50 adet beyaz çadır (çerge) yapılmıştır. Bu çadırlar için toplam 13.000 Küpköyi kirpası Mehterhane'den istenmiştir.

32 BOA., C.AS.277-11495., H.1207 senesinde Levend Çiftliğinde yaptırılacak olan çadırlar için Mehterhane mevcudundan 500 zira kirpas gönderilmiştir.

33 BOA., C.AS. 841-35880., H.1215 senesinde Orduya gönderilecek olan unun nakli sırasında gerekli olan 2265 adet çuval, Moskov kirpası denen kirpas türünden yapılmıştır. Yapılan çuvalın adet fiyatı 53 para olup, seferiye akçesinden toplamda 3000 kuruş ödeme yapılmıştır. 34 BOA., C.AS. 983- 42891., H.1165 senesinde Bender kalesinde bulunan siyah barutun perdaht (cila) edilmesi için kirpas temin edilmiştir.

35 Mehmet Zeki Pakalın, "Hartuç Kesesi" Osmanlı Tarih ve Deyimleri Sözlüğü, C.1, Milli Eğitim Basımevi, İstanbul, 1983, s. 750.

36 BOA., C.AS. 713-29925., H.1188 senesinde Hartuç yapımı için gerekli olan kirpas için ilk olarak 20 top kirpas temin edilmiş olsa da bu miktar yeterli olmayıp, 30 top kirpas 71 kuruş 10 paraya mübayaa edilerek, Topçu Ocağına teslim edilmiştir.

37 Cenab-1 Peygamberin, Liva-i Şerif, Liva-1 Saadet, Sancağ-1 Şerif adı verilen sancağı, ordu ile sefere gittiği vakit hizmet ve muhafazasına memur olan askerler için kullanılan bir tabirdir. 
Muhammed' in Sancă̆-1 Şerifini muhafaza etmekle görevli olan askerlerin çeşitli ihtiyaçlarının karşılanmasında da kullanılmıştır. Bu amaçla istenen kirpasın bir topu dokuz zira uzunluğunda olması istenmiştir. ${ }^{38}$ Serasker ve Liva-1 Şerif takımı için alınacak kirpaslar tek tip olmayıp kırmızı ve beyaz olarak ayrılmıştır. Ayrıca alınacak kirpas miktarı fazla ise kirpasın temini birkaç bölgeden sağlanmıştır. ${ }^{39}$ Alım yapılacak yerlerin arasında Diyarbakır, Soma ve Halep gibi önemli kirpas üretim merkezlerinin dışında Bergama ve Siroz gibi bölgeler de bulunmaktadır. ${ }^{40}$

Kirpas, ordu içerisinde bulunan çeşitli asker gruplarının yazlık ve kışlık kıyafetlerinin hazırlanması sırasında da yoğun bir şekilde kullanılmıştır. ${ }^{41}$ Kıyafetlerin hazırlanması sırasında gerekli olan kirpasın uzunluğu belirtilmiş olup ${ }^{42}$, yapılacak alımlar sonunda ödenecek olan kirpas bedeli on binlerce kuruşu aşmıştır. ${ }^{43}$

Kirpasın bu kullanım alanları dışında ordu içerisinde çeşitli kullanım alanları da olmuştur. Özellikle ordu içerisinde bulunan Çerkes ve Abhazlar tayinat giderleri için para yerine kirpası tercih etmişlerdir. Bu askerlerin tayinat paralarına mukabil aylık olarak belli miktar kirpas verilmiştir. ${ }^{44}$ Yine sefer sırasında ordu içerisinde bulunan Abhaz ve Çerkes kabilelerini orduda istihdamlarının devamını ve sadakatlerini sağlayabilmek için bedeli on binlerce kuruşu bulan çeşitli hediyelerin gönderilmesi bölgede bulunan görevliler tarafından istenmiştir. Gönderilmesi istenen hediyeler arasında kirpas da yer almıştır.45

Kirpas, sefer alanı dışında Topkapı Sarayı ve bazı önemli yapıların içerisinde veya önünde bulunan topların ${ }^{46}$ ve ülke güvenliğinde önemli bir yere sahip olan kalelerde bulunan topların korunması içinde kullanılmıştır. Kalelerde ve açık

Mehmet Zeki Pakalın, "Liva-ı Şerif Takımı”, Osmanlı Tarih Deyimleri ve Terimleri Sözlüğü, C.2, Milli Ĕ̆itim Basımevi, İstanbul, 1983, s. 367.

38 BOA., C.AS. 676-28379.

39 BOA., C.AS. 881-37836.

40 BOA., C.AS. 911-39301.

41 BOA., C.AS. 117-5279.

42 BOA., C.AS. 249-10414., Askerlerin yazlık elbiseleri için istenen kirpasların topu 5 ziradır.

43 BOA., C.AS. 52-2414., Asakir-i Mansure-i Muhammediye ordusuna H.1245 y1lında ruz-1 hızırda verilecek olan elbiselerin hazırlanması için gerekli olan 65.550 top kirpasın teminini Gelibolu muhafızı Ali Paşa adındaki kişi sağlamıştır. Bu miktarda kirpas için 25.000 ve 30.000 kuruş, toplamda 55.000 kuruş ödeme yapılmıştır

44 BOA., C.AS. 692-29057.

45 BOA., C.DH. 255-12743.

46 BOA., C.AS., 1056-46429., H.1226 senesinde, Saray-1 Hümayun (Topkap1 Saray1) ve Kurşunlu Mahzende bulunan topların için her sene Tersâne-i Âmire'den 3,5 kantar köhne kirpas verildiği yazılmıştır. 
alanda bulunan topların zaman içerisinde yağmur ve kar suları nedeniyle paslanmaması için üzerlerinin örtülmesi gerekmiştir. Üzerlerine örtülecek kirpaslar, Tersâne-i Âmire' de bulunan çeşitli gemilerde kullanılmış eski yelken bezlerinden temin edilmiştir. Ayrıca eski kirpasların yanında lüzuma göre yeni kirpas istenmiştir. ${ }^{47}$ Yapılan gönderilerde her sene hangi kaleye ne miktar da (kantar olarak) yeni ya da eski kirpasın gönderildiği belirtilmiştir. ${ }^{48}$

\section{Sonuç}

Yaşadığı devrin büyük kara ordularından birine sahip olan Osmanlı Devleti, bu ordunun her türlü lojistik ihtiyacını en iyi şekilde karşılamaya çalışmıştır. Ordu için gerekli olan lojistik maddelerden biri olan kirpas denilen kumaş türü, Osmanlı kara ordusunda yoğun bir şekilde kullanılmıştır. Özellikle seferler sırasında Mehterhane tarafından, sefere katılan on binlerce askerin ve sultanın konaklaması için yapılan çeşitli türden çadırları düşündüğümüzde, kirpas denen bu kumaşın ordu açısından ne denli hayati bir öneme sahip olduğunu görmüş oluruz. Sefer sırasında sadece çadırların yapımında kullanılmayan bu kumaş türü, ordu içersisinde bulunan çeşitli askeri grupların kıyafetlerinin hazırlanmasında ve hatta bazı askeri grupların tayinat bedelinin mukabili olarak verilmesinde de kullanılmıştır. Ayrıca ülke içerisinde bulunan bazı önemli yapılara ve kalelere yerleştirilmiş olan topların zaman içerisinde paslanmaması için de kirpas yoğun bir şekilde kullanılmıştır.

Devlet, gerekli olan kirpası uzunca bir süre dışa bağlı kalmadan kendi öz kaynaklarına bağlı kalarak, Diyarbakır ve Soma bölgeleri başta olmak üzere Osmanlı coğrafyasının genelinde üretebilme kabiliyetini göstermiştir. Bu durum, devleti stratejik açıdan güçlü duruma getirmesinin dışında, önemli miktarda paranın ülke içerisinde kalmasını da sağlamış ve Anadolu'nun çeşitli bölgelerinde kirpas üretiminin yaygınlaşmasına ve üretim bölgelerinde ekonomik bir canlanmaya neden olmuştur.

\section{Kaynakça}

\section{I- Arşiv Belgeleri}

Türkiye Cumhuriyeti Cumhurbaşkanlığı Devlet Arşivleri Başkanlığı Osmanlı Arşivi (BOA.)

\section{Ali Emiri:}

Sultan III. Ahmed (AE.SAMD.III): 147-14414, 218-21030.

47 BOA., AE.SABH.I. 248-16583.

48 BOA., C.AS. 1128-50082., H.1193 senesinde Rumelihisarı'nda bulunan toplar için Tersane-i Âmire' den 1 kantar köhne kirpas istenmiştir. 
Sultan I. Abdiulhamid (AE.SABH.I): 248-16583.

Sultan II. Mahmud (AE.SMHD.III): 111-9532.

Cevdet:

Askeriye (C.AS): 52-2414, 104-4714, 117-5279, 170-7454, 249-10414, 277-11495, 385-15916, 561-23568, 588-24760, 676-28379, 692-29057, 713-29925, 841-35880, 881-37836, 911-39301, 974-42449, 983-42891, 1056-46429, 1128-50082, 111449355.

Bahriye (C.BH): 87-4192, 104-5034, 259-11997.

Dahiliye (C.DH): 255-12743.

İktisat (C.İKTS): 11-539, 17-808.

Maliye (C.ML): 4-146.

İBNÜLEMIN:

Dahiliye (İE.DH): 16-1450.

Saray (IE.SM): 24-2502.

\section{Araştırma Eserler}

AGOSTON, Gabor, Osmanlı'da Strateji ve Askerî Güç, (Çev. M. Fatih Çalışır), Timaş Yayınları, İstanbul, 2015.

AKSAN, Vırgına H., Kuşatılmış Bir İmparatorluk Osmanlı Harpleri 17001870, (Çev. Gül Çağalı Güven), Türkiye İş Bankası Kültür Yayınları, İstanbul, 2011.

AYDIN, Yusuf Alperen, "XVII. Yüzyıl Başlarında Osmanlı Donanması ve Tersâne-i Âmire'de Lenger ve Yelken Bezi Üretimine Başlanması" Tarih Dergisi, S.49, İstanbul, 2010.

BOSTAN, İdris, Osmanlı Bahriye Teşkilâtı: XVII. Yüzyılda Tersâne-i Amire, T.T.K., Ankara, 2003.

CHASE, Kenneth, Ateşli Silahlar Tarihi, (Çev. Füsun Tayanç), Türkiye İş Bankası Kültür Yayınları, İstanbul, 2008.

GENÇ, Mehmet, Osmanlı İmparatorluğunda Devlet ve Ekonomi, Ötüken, İstanbul, 2014.

İNALCIK, Halil, Osmanlı İmparatorluğu'nun Ekonomik ve Sosyal Tarihi, C.1, Eren Yayınları, İstanbul, 2009.

İşBİLIR, Ömer, "Osmanl Ordularının İaşe ve İkmali: I. Ahmed Devri İran Seferleri Örneği", Türkler, C.10, (Edt. Hasan Celal Güzel) Yeni Türkiye Yayınları, 2002. 
PAKALIN, M. Z., Osmanlı Tarih Deyimleri ve Terimleri Sözlüğü, Milli Eğitim Basımevi, İstanbul, 1983.

PANZAC, Daniel, Osmanlı Donanması (1572-1923), (Çev. Ahmet MadenSertaç Canpolat), İş Kültür Yayınları, İstanbul, 2018.

TABAKOĞLU, Ahmet, Osmanlı Mali Tarihi, Dergah Yayınları, İstanbul,2016.

UZUNÇARŞILI, İsmail Hakkı, Osmanlı Devleti Teşkilâtından Kapukulu Ocakları, C.I, T.T.K., Ankara, 1988.

YARAMIŞ, Ahmet, "Mehterhâne-i Âmire Ocağı'nın Islahı (1826)", AfyonKocatepe Üniversitesi SBD., C.15-S.1.2013. s.31-44.

YILDIZ, Gültekin, "Kara Kuvvetleri", Osmanlı Askeri Tarihi Kara, Deniz ve Hava Kuvvetleri 1792-1918, (Edt. Gültekin Yıldız), Timaş Yayınları, İstanbul, 2017. 


\section{Ekler}

Ek-1. Yenice-i Göksu Kalesinde bulunan topların örtülmesi için Tersane-i Amire'den kirpas istenmesine dair (BOA. AE.SABH.I - 248-16583)

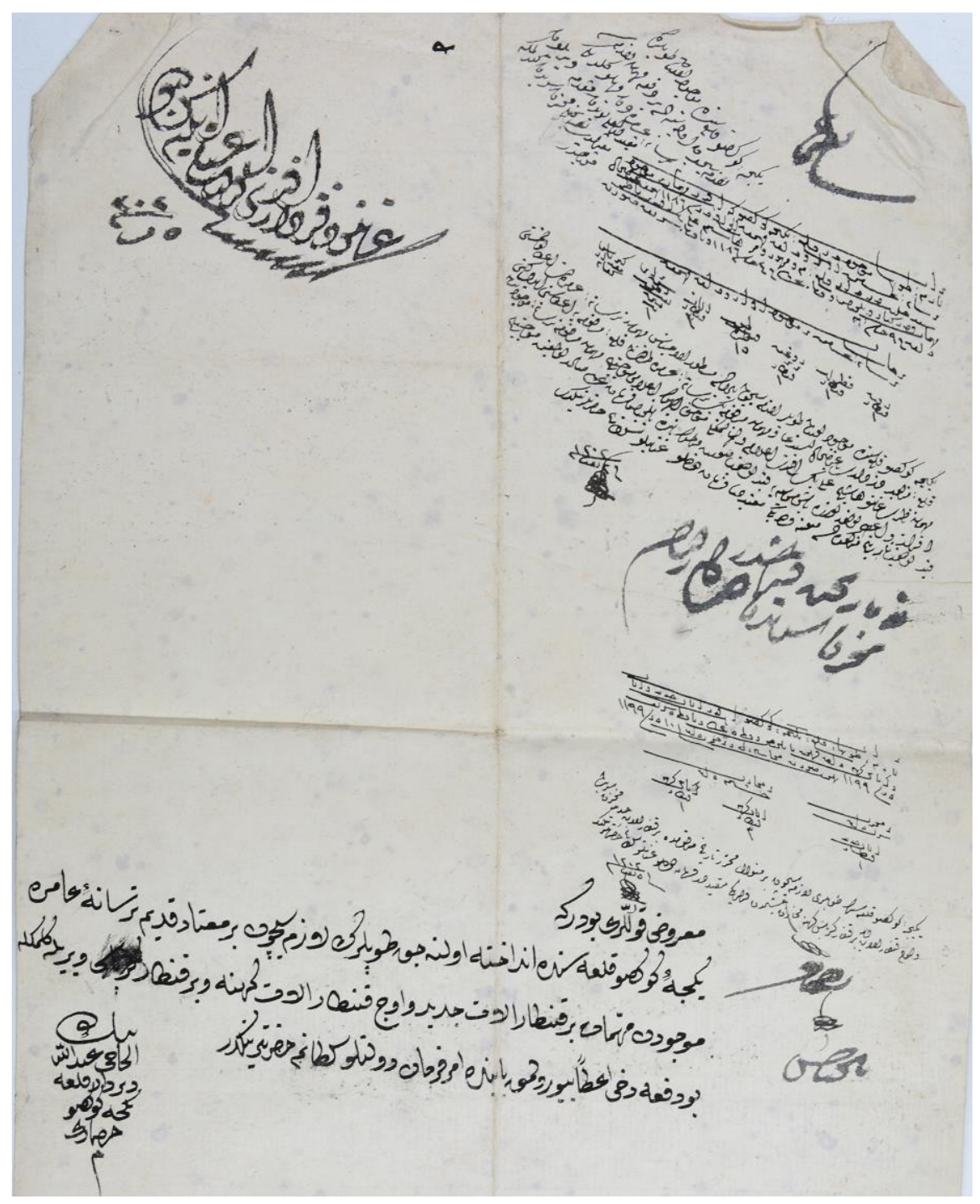


Ek-2. Çerkes ve Abhaz kabilelerine kirpas verilmesine dair (BOA. C.DH. 255-1743)



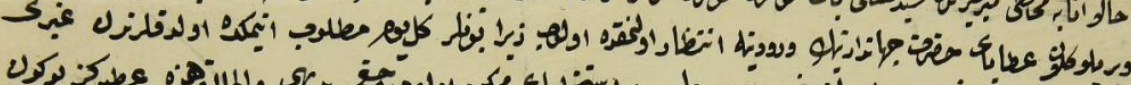

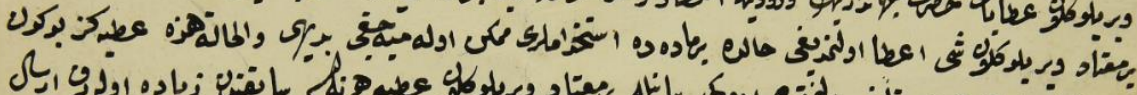

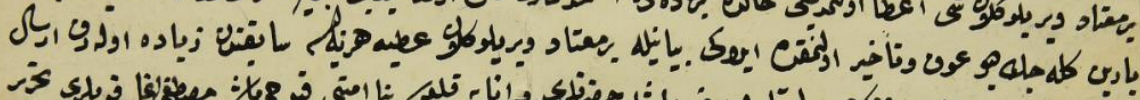

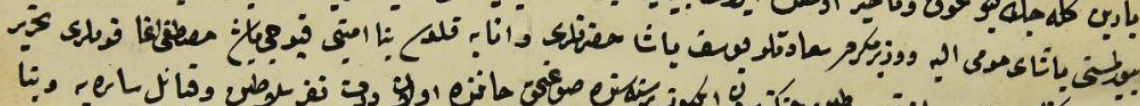

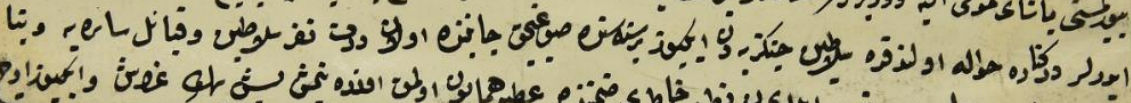

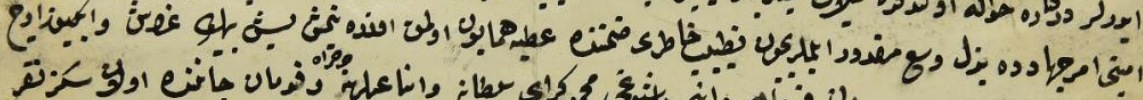

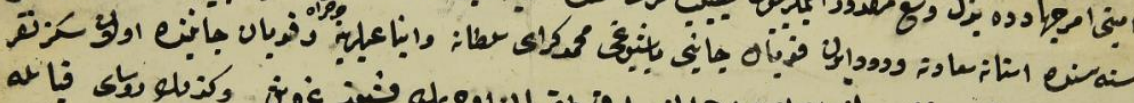

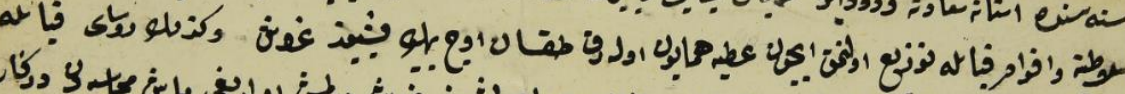

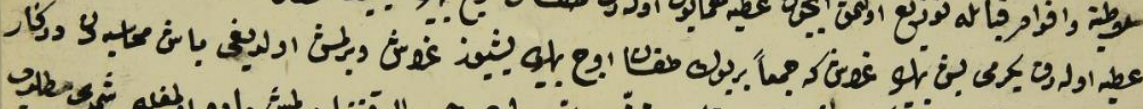

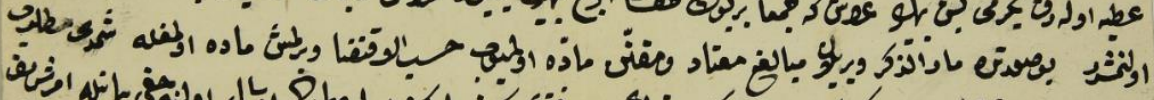

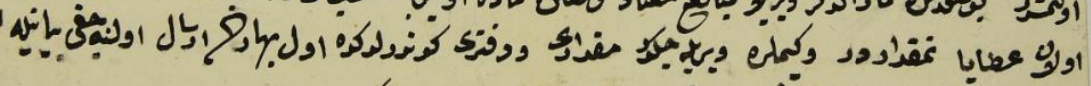

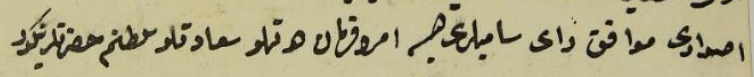


Ek-3. Diyarbakır'dan Mehterhaneye kirpas gönderilmesine dair (BOA. C.İKTS.17-808)

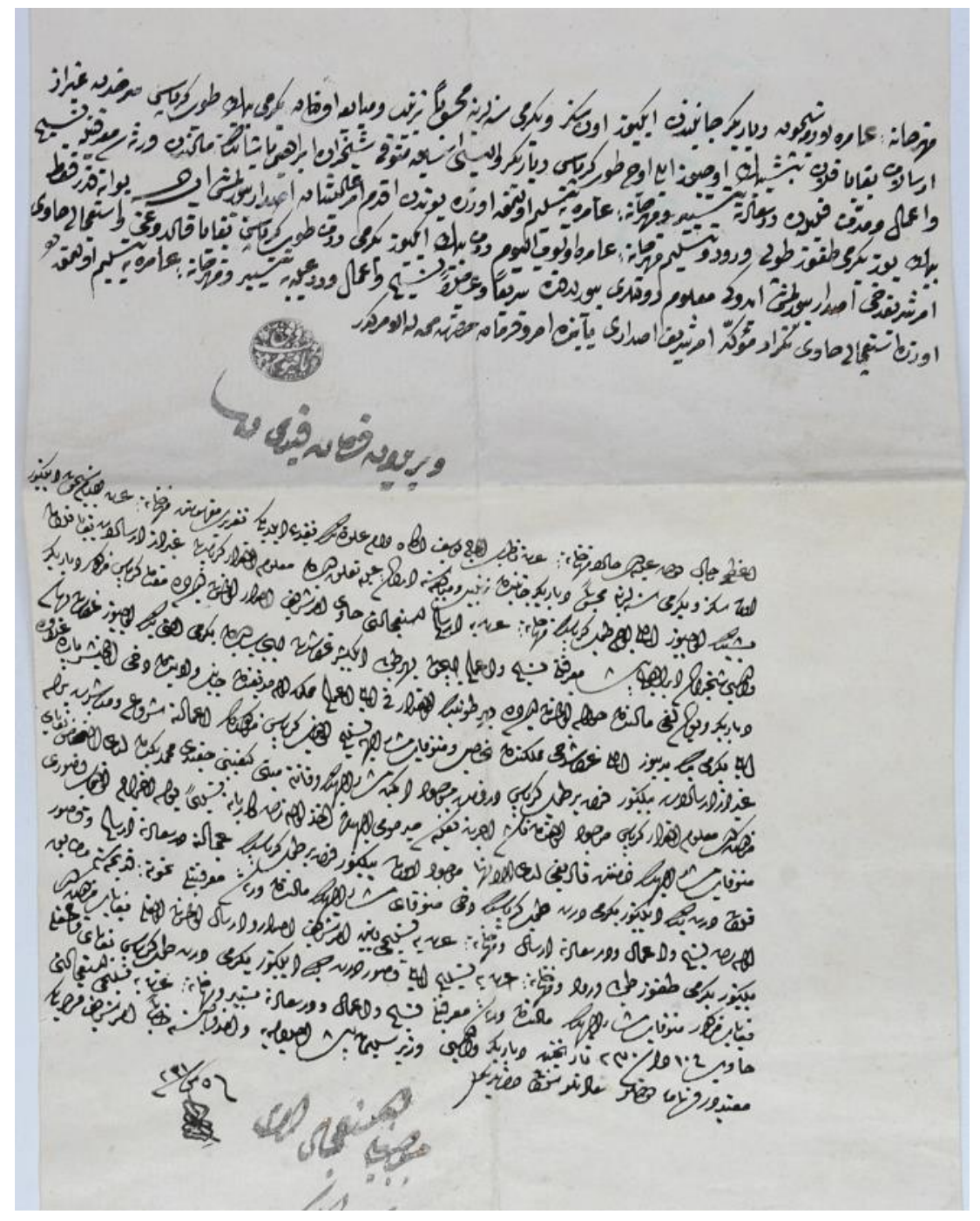

